\title{
How user personality and social value orientation influence avatar-mediated friendship
}

\begin{abstract}
Purpose We study avatar-mediated friendships in a novel virtual environment where users are unaware of each others' real identity. In particular we examine the number of friendships made, the number of attempts to make friends and the number of times a user was selected for friendship.

Design/methodology/approach In a field experiment, 179 participants interact inside a new virtual world designed to capture behavioral data automatically.

Findings Findings suggest that personality and values influence the number of friends and friendship invitations made but not the number of friendship invitations received. Only the personality trait conscientiousness exhibits homophily.

Research limitations/implications We discuss how users might perceive other users' characteristics and find evidence of differences in avatar chat, appearance and movement across personality traits and values. Our paper contributes to a growing body of work on questions regarding the origin and evolution of social network structures.

Originality/value This is the first time that virtual world friendship, user personality and values have been studied together in this way.

Keywords: computer-mediated communication and collaboration, virtual world, user studies
\end{abstract}




\section{Introduction}

Online social networking is an important topic for Information Systems (Agarwal et al., 2008). This paper considers one particular form of social networking: avatar-mediated networking in a virtual world where those involved are unaware of others' real identities. A virtual world is a persistent computer-mediated environment in which many users can synchronously interact (Bell, 2008). They are designed to create a new 'reality' for users in contrast to other virtual experiences such as Facebook that layer digital and physical content together (Jurgenson, 2012). This makes the experience of using a virtual world fundamentally different from most other online experiences. While virtual worlds have not realized their potential as an organizational tool for collaborative work and team communication (Wasko et al., 2011) they have firmly retained a use in entertainment (de Castell et al., 2014; Bainbridge, 2010) and found a new niche in education and training (Cohen et al., 2012; Connolly et al., 2012; Bohannon, 2010). Topics taught in virtual worlds include management, healthcare, geography, history, languages, computing and mathematics (Ghanbarzadeh et al., 2014).

These uses - education and recreation - are typically social activities. They usually involve groups of people who need to cooperate and collaborate. Therefore we are interested in understanding social interaction inside virtual worlds. Following Selfhout et al. (2010) and Ingram and Morris (2007) we examine micro-encounters (Collins, 2004), i.e. relationships among people who have just met. The research goal of the paper is to examine how user personality and social value orientation (SVO) influence these social connections.

We study the behavior of 179 individuals as they engage in open-ended interaction in a novel world set up and run by the research team. All participants entered the world from a computer lab which affords control over who took part and generates 'ground truth' knowledge about them (Granhag and Vrij, 2005). The fact that the world is controlled by the research team permits full access to the server logs from which a number of metrics describing participants' behavior are extracted.

Users are represented in a virtual world by an avatar. Almost all worlds include a facility for social networking typically labelled friendship. We define avatar-mediated friendship as a directed social connection between two users through their avatars as illustrated in Figure 1. 


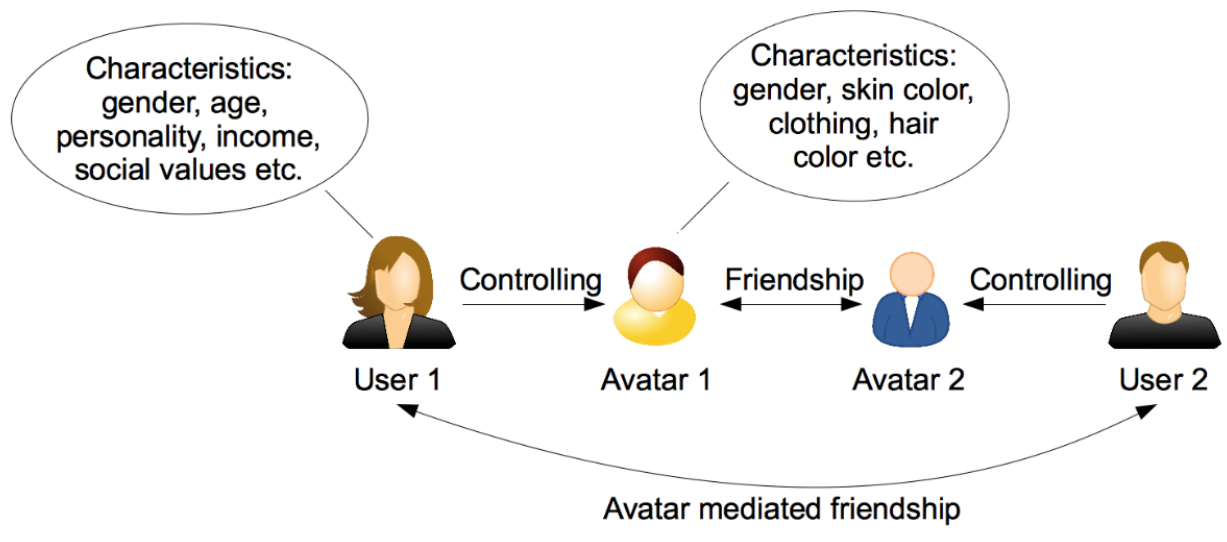

Figure 1: When Avatar 1 becomes friends with Avatar 2, User 1 forms an avatar-mediated friendship with User 2. The relationship between user and avatar is complex and is explored fully in Section 2.1; in the figure it is illustrated as one of control: a user controls their avatar. The relationship between avatar and avatar is labeled 'friendship' in most virtual worlds. The relationship between user and user is avatar-mediated friendship.

The relationship is directed because one user must initiate it by inviting another to become their friend. The concept is examined in detail in Section 2 but in brief, it allows users to connect with one another via their avatars. Previous research has examined the relationship between a user and their avatar (Coulson et al., 2012; Messinger et al., 2008a; Bessière et al., 2007; Taylor, 2002) and between avatars (Chesney et al., 2014; Utz, 2000) but our interest here lies in the relationship between users.

While there are a number of user characteristics that could be studied as mediators of avatar friendship we choose to start with two: personality and SVO. Both have been found to be important constructs in previous user behavior research leading to calls to examine them further (Jadin et al., 2013; Lounsbury et al., 2007). The origin and evolution of social network structures are open and important questions (Ahuja et al., 2012) and an understanding of virtual world network evolution would lead to greater understanding of these phenomena in the context of a virtual world.

\section{Theory}

In this section we compare social media connections with real world social connections in order to define and describe our main construct, avatar-mediated friendship. We highlight shared activity as a key distinguishing element of avatar-mediated friendship and examine 
personality and SVO to explain why we expect them to influence avatar-mediated friendship. Finally we develop hypotheses about the relationships between personality, SVO and avatarmediated friendship.

\subsection{Avatar friendship}

The term 'social networking' includes a multitude of concepts. For instance the LinkedIn platform exists to build business networks and many users operate with the philosophy 'more is better' (Ollington et al., 2013). In contrast Facebook encourages numerous friendship 'strategies' including strengthening existing offline friendships (Yang and Brown, 2013) and building self-esteem through connections (Lee et al., 2012). A number of authors have highlighted differences between these and real world friendship. Early work (e.g. Cocking and Matthews, 2000; Rheingold, 2000) saw the key difference in that virtual friends have no possibility of non-voluntary signals (such as blushing) which are an essential part of 'true' friendship. Barney (2004) and Borgmann (2004) highlighted a lack of physical practices and recently, philosophers have picked up on this point. Vallor (2012) argues that friendships initiated through media such as Facebook and Twitter can approximate most dimensions of real world friendship. Social media allow for the development of reciprocal exchanges and empathy to develop between two friends. Further, they permit a kind of connected selfdiscovery where a person comes to develop accurate self-representations of themselves and their position in the world through connections with others. However such media are weaker in facilitating shared experiences similar to online connections lacking 'physical practices'. It is this aspect that sets avatar-mediated friendship apart from other forms of online social networking.

While virtual friendships may not equate to real friendships they may resemble them more than friendships formed in other modes of online communication (Munn, 2012). The reason is that a virtual friendship is based in part on shared activity whereas other online experiences share only communication. Thus a virtual world facilitates an approximation of a shared experience that Vallor (2012) sees as a key distinction between social media and real-world friendships. For instance, real-world friends can go fishing together, virtual-world friends can go virtual fishing together but friends in a chat room can only text each other 
about going fishing.

This view has considerable support. Regardless of the lack of non-voluntary disclosure, avatar-mediated friendship can enhance well being (Søraker, 2012). Virtual friends can share experiences which increases positive emotions (Gable et al., 2004). The fact that nonvoluntary signals are not possible may in fact lead to an increase in voluntary disclosure which tends to enhance friendship (Briggle, 2008; Yee, 2006). Like Facebook, virtual worlds can strengthen real-world friendship (Schiano et al., forthcoming) and benefit social development (Koot and Garde, 2013). Interestingly, the possibility of shared experience allows for comparison between virtual-world connections and open source software development communities. These also feature a shared activity, i.e. writing code. Some studies (Bagozzi and Dholakia, 2006; Orucevic-Alagic and Host, 2014) have explored this idea but surprisingly personality and SVO have so far not been looked at.

Unlike typical real-world relationships an avatar-mediated friendship has a directed component as one user must give another user an friendship invitation. This creates three types of virtual world relationship: a mutual connection between two people, no connection between two people meaning no desire to form a connection from either side exists, and an unrequited connection where a participant sends a friendship request which is ignored.

\subsection{Personality and SVO}

We consider two broad user characteristics: personality and values. Personality is "a dynamic organization, inside the person, of psychophysical systems that create a person's characteristic patterns of behavior, thoughts, and feelings" (Wrosch and Scheier, 2003, p.60). In short, it is a person's internal psychological predispositions to act, feel or think in a certain way. Each individual has a consistent and typical pattern of emotion, thought and behaviour in everyday life given by their personality traits. Personality theories conceptualize individual differences in terms of traits. Traits are psychological characteristics such as introversion, aggression, demureness etc. Differential psychologists study personality by

using taxonomies which classify the main personality traits by which people differ. The Big Five model (Digman, 1990; Goldberg, 1993) is one of the best-developed and most useful taxonomies and enjoys considerable empirical support (Moore and McElroy, 2012; 
Barrick et al., 2001; Costa and McCrae, 1992). The five personality factors have been labeled conscientiousness, extraversion, agreeableness, openness and neuroticism. They are well known but will now be briefly summarized.

Conscientiousness can be defined as the 'will to achieve' (Digman and Inouye, 1986). Those with high conscientiousness are well organised, show self-discipline and plan their behavior. Extraversion was reported by Eysenck (1947) in his early 'Big Two' model of personality. Those scoring high on extraversion are outgoing and show high energy and sociability. Agreeableness captures human characteristics such as altruism and emotional support. Those with high agreeableness show friendly compliance, while those that score low on this trait show hostile non-compliance (Digman and Takemoto-Chock, 1981). Openness describes behaviors such as appreciation of culture, creative interests and educational aptitude. Those with high openness are curious and open to new experiences, while those with low openness are cautious and less adventurous. Neuroticism was also reported by Eysenck (1947). It captures emotional stability and runs from nervous to confident.

Values are beliefs about desirable outcomes (Hofstede, 1994; Maio et al., 2001). A number of taxonomies of values exist, each with its own metric for measuring them (e.g. Schwartz, 1994; Hofstede, 1994; Rokeach, 1973). Our interest here lies in social values. In the literature, Social Value Orientation is defined as an individual's preference for a particular distribution of outcomes to self and to others (McClintock, 1978; Messick and McClintock, 1968). There are four classes of SVO. First, equality is the orientation to minimize the difference between own and others' outcomes. Second, cooperation is the orientation to maximize joint outcomes. Third, individualism is the orientation to maximize own outcomes with no regard for others' outcomes. Finally, competition is the orientation to maximize the difference between own and others' outcomes and to seek relative advantage over others. Those who are oriented towards equality and cooperation are termed 'pro-socials', whereas those who are individualistic and competitive are termed 'pro-selfs' (Liebrand et al., 1986a,b; Van Lange and Liebrand, 1991; Van Lange et al., 1997b). In social dilemma studies, pro-socials have consistently been found to make more cooperative decisions and to exercise more personal restraint compared to pro-selfs (Liebrand and van Run, 1985; Liebrand et al., 1986a; Van Lange and Liebrand, 1991). Pro-socials are described in the literature as emphasizing morality, equality, 
justice, reciprocity and agreeableness. Pro-selfs, on the other hand, are described as emphasising might, strength and intelligence (Liebrand et al., 1986a,b; Van Lange and Liebrand, 1991; Van Lange et al., 1997b). Considerable empirical support now exists for SVO which has been found to predict behaviors including helping, sacrifice and cooperation (Van Lange et al., 1997a; Van Vugt et al., 1995; Van Lange and Kuhlman, 1994; Sattler and Kerr, 1991; McClintock and Allison, 1989; McClintock and W.B.G., 1988; Beggan et al., 1988; Liebrand and van Run, 1985; Kuhlman and Marshello, 1975; Chuah, 2008).

Personality and values are distinct types of constructs (Veage et al., 2011; Parks and Guay, 2009; Parks, 2007; Roccas et al., 2002): values relate to what we believe we ought to do, while personality relates to what we naturally tend to do (Parks, 2007). Personality traits are relatively innate dispositions (Olver and Mooradian, 2003) while values are acquired and maintained through socialization (Nisbett, 2010). While both have been found to be important constructs in previous user behavior research, personality and values have rarely been studied together (Parks and Guay, 2009). Many studies have found personality to be predictive of both technology adoption and Internet behavior (Ross et al., 2009; Devaraj et al., 2008; Guadagno et al., 2008; Amichai-Hamburger et al., 2008; Wherli, 2008; McElroy et al., 2007; Amichai-Hamburger, 2002). It has also been studied in IS research areas (Lounsbury et al., 2007). While SVO has not been used extensively in previous IS research it has been found to be important in a few studies. Both Marks et al. (2008) and Jadin et al. (2013) find it predictive of knowledge sharing behavior and Hsieh et al. (2013) find it relates to willing to assist newcomers in online communities. In addition, personality and SVO are known to influence real world friendship and, as will be explained in the next sub-section, both could potentially be perceived by others through an avatar ${ }^{1}$. Therefore they may both be expected to influence avatar-mediated friendship.

Values are prone to social influence (Bardi and Schwartz, 2003) and must first be cognitively activated in order to influence behaviour (e.g. Schwartz, 2010), for example by priming. For instance, Verplanken and Holland (2002) find that individuals make decisions consistent with their values only after these were activated by making participants think about them.

\footnotetext{
${ }^{1}$ To be clear on what this is suggesting: looking back at Figure 1, User 1 might be able to perceive the personality and SVO of User 2.
} 
This means humans need to rationally consider options in order for values to 'shine through' (Connor and Becker, 1994), a process sometimes known as slow thinking. Fast and slow thinking refer to decisions made spontaneously and after consideration respectively. They have long been studied by psychologists (see Kahneman (2011) for an excellent overview). Priming occurs naturally when values are the primary focus of attention or if they are implied by a situation (Verplanken and Holland, 2002). In this study, social values are primed by putting participants in a competitive socialization task.

\subsection{Perceiving a user's personality and SVO through their avatar}

If personality and SVO are to have an impact on a user's friendship decisions then they must be transmitted through an avatar in a way that other users can detect. If such signals cannot be transmitted then personality and SVO cannot have an effect. The notion of virtual world avatar transmission has not previously been fully studied but it is not unrealistic. Accurate judgements of personality can be made based on observing aspects of an individual's life such as their bedroom (Gosling et al., 2002) or music collection (Rentfrow and Gosling, 2006), and assessments of personality just from observing online behavior (such as email content and personal homepage design) have been found to have some validity (Marcus et al., 2006; Back et al., 2008; Gill et al., 2006).

The relationship between avatar and user is complex (Yee and Bailenson, 2007; Nowak and Rauh, 2006) but studies suggest that users may chose avatars that are similar to themselves (Messinger et al., 2008b; Bessière et al., 2007) or that represent the physical identity they would like to possess i.e. their 'ideal self' (Taylor, 2002; Bessière et al., 2007). This would indicate that users are trying to show aspects of themselves through their avatar. In any case avatars are not usually designed arbitrarily (Ducheneaut et al., 2009) and users often use others' avatars as a proxy for that user during interaction (Benford et al., 2001; Taylor, 2002; Talamo and Ligorio, 2001).

Perhaps the most likely way that user characteristics could be perceived during avatarmediated interaction is through their text chat. Previous studies have found that online text chat can indeed reveal personality (Van Zalk et al., 2011) and this is supported by linguistics research which suggests that verbal cues can reveal characteristics such as level of intelligence 
(Denissen et al., 2011). Yee et al. (2011b) find empirical evidence that chat in Second Life does reveal aspects of personality, as does avatar behavior and movement (such as distance walked). In a separate study of World of Warcraft players, Yee et al. (2011a) find that a wide range of behavioral indicators can be used to infer a player's personality.

The VERUS project (Dieterle and Murray, 2010) aimed to identify what can be determined about a user solely from observing their avatar's behaviour drawing on quantitative and qualitative datasets created from a number of virtual worlds. Findings show that characteristics including gender, age, ethnicity, education, income and native language can all be predicted with high accuracy from a number of in world cues including avatar chat, avatar movement and avatar design/appearance. Therefore user characteristics could potentially be perceived through an avatar and we draw on this conclusion to develop hypotheses about avatar-mediated friendship.

A counter argument is the claim that entering a virtual world and creating an avatar generates a 'virtual world personality' that users take on without changing their real underlying traits, similar to acting in a role play. This question has previously been examined. In an effort to validate the use of virtual worlds for reliable psychological testing and clinical applications Aas et al. (2010) had virtual world users complete a Big Five personality questionnaire as their avatar via a virtual interactive testing screen within Second Life. Seven months previously the same users had completed the same personality questionnaire in the real world. No difference was found along any dimension of personality. This is not beyond criticism but it does give some evidence to suggest that users do not create a virtual personality for their avatar.

\subsection{Hypotheses}

To develop hypotheses we draw on trait theory, the theory of person construal and the theory of homophily. We use trait theory to explain why personality and SVO may influence the friendship requests a user sends. We use the theory of person construal to explain why personality and SVO may influence the friendship requests a user receives. We use homophily to explain why personality and SVO may influence the friendships a user makes.

Trait theory sees personality made up of habitual patterns of behavior, thought and 
emotion. These patterns are relatively stable over time and influence behavior. The "personsituation debate' considers whether an individual or the situation they find themselves in is more influential in determining their behavior. Trait psychologists believe that people have consistent personalities that guide their behavior across situations.

The theory of person construal (Freeman and Ambady, 2011) explains how individuals perceive, comprehend, and interpret others around them, particularly the behavior or actions of others towards them. Construal is used particularly when meeting strangers for the first time. We draw on the theory of person construal to explain why personality and SVO might impact on the number of friendship invitations received. Person construal models how humans reason about other people as individuals categorizing sensory input received from others. In the context of a virtual world this means their text chat or avatar appearance. These categories are immediately and automatically assessed against existing knowledge coming from stereotypes and prior experience to form an impression on a person including impressions of their personality and values.

Homophily explains connections between people through similarities between them. Homophily is said to exist when individuals tend to associate with others who they perceive as similar (Lazarsfeld and Merton, 1954). Such associations have long been observed by sociologists (Moody, 2001) and have been found in age, sexuality, race, gender, income, education level, religion, status and competence (Carley, 1991; Ibarra, 1993; Laumann, 1966; McPherson and Smith-Lovin, 1987). Homophily is an important concept in IS being used to explain information diffusion, technology adoption and team performance (Thelwall, 2009; Ruef et al., 2003; Hinds et al., 2000; McPherson et al., 2001; Iribarren and Moro, 2011).

Homophily has been found to arise both by individual choice, where friends are chosen because similarities exist, and by social influence, where existing friends change each other's behavior over time to become more similar to each other (Easley and Kleinberg, 2010). An example of a social influence theory is Social Identity Theory (Tajfel, 1978) which proposes that individuals gain a social identity from the groups they belong to and therefore adopt similar behavior to the others in the group in an attempt to foster feelings of belonging. Several individual choice theories have been proposed. Similarity-attraction (Byrne, 1971) posits that individuals seek consistency and select similar individuals to form relationships 
with to provide this. Self-categorisation (Turner, 1987) suggests that individuals define themselves along dimensions such as age and race and seek out others in the same category or categories to legitimise that identity.

An alternative view suggests that homophily results from pre-existing 'structures' that somehow tend to bring similar people together (Ingram and Morris, 2007). Such structures include pre-existing relationships and institutions or bureaucracy which similar people gravitate to. Examples include a university that attracts people with the same level of education, a discount store that brings together people from the same socio-economic background and a church that brings together people with similar religious beliefs. Pre-existing structures have been found to have a significant effect on inter-organization networks (Ahuja et al., 2009; Gulati, 1995).

The personality trait most associated with sociability is extraversion. Those scoring high on extraversion are more outgoing and social, and therefore extraversion is thought to be highly related to friend seeking behavior (Denissen and Penke, 2008; Fleeson et al., 2002). However the evidence is inconsistent. Some studies of online communication suggest that both extraverts and introverts (i.e. individuals at both ends of the extraversion scale) are motivated to create more friendships (Jochen et al., 2005). Selfhout et al. (2010) examine this further and find that extraversion is related positively to friend seeking behaviour but not to being selected as a friend. Their study is similar to ours in that they examine just-acquainted individuals. Therefore we test for a positive relationship between extraversion and number of friends as well as number of friendship requests made, but not between extraversion and friendship invitations received.

H1a Extraversion will be positively related to friendship.

H1b Extraversion will be positively related to the number of friendship requests made.

H1c Extraversion will not be related to friendship invitations received.

Agreeableness is also thought to impact on friendship as those with high agreeableness show more prosocial behaviors such as altruism and cooperation (Nettle, 2006; Holmes, 2002), characteristics that tend to be valued by friends. In a test of this, Scholte et al. (1997) find both extraversion and agreeableness to be associated with being 'accepted by peers'. However it is unclear whether this influences being selected as a friend or selecting 
friends (Sprecher and Regan, 2002). At least one study has found a relationship between agreeableness and being invited to become friends (Selfhout et al., 2010). Given this we test for a relationship between agreeableness and number of friends, number of friendship requests and number of friendship invitations. The latter is hypothesized as we expect users to be able to perceive agreeableness through an avatar as described in Section 2.3.

H2a Agreeableness will be positively related to friendship.

H2b Agreeableness will be positively related to the number of friendship requests made.

H2c Agreeableness will be positively related the number of friendship invitations received.

A similar picture appears with conscientiousness. While this trait has not received as much attention it was associated with peer acceptance in one study of relationships among children (Jensen-Campbell et al., 2007). Some support for this is offered by Selfhout et al. (2010) who find a positive although statistically insignificant association between conscientiousness and making friends.

H3a Conscientiousness will be positively related to friendship.

H3b Conscientiousness will be positively related to the number of friendship requests made.

H3c Conscientiousness will be positively related to the number of friendship invitations received.

Other personality traits have not been found to be related to number of friends but are still thought to play a part in the development of friendship. Similarity-attraction theory (Byrne, 1971), social identity theory (Tajfel, 1978) and self-categorisation theory (Turner, 1987) all predict that friends will have similar personalities as measured by all five personality traits (Selfhout et al., 2010).

We expect to see personality homophily here as we expect users to be able to perceive each other's personality through their avatar as explained in Section 2.3.

$\mathrm{H}_{4}$ Users will create friendship links with users who have similar personality traits.

The explicit influence of SVO on number of friends, friend requests and friend invitations has not been studied before. SVO is known to impact on cooperation (Balliet et al., 2009), helping (McClintock and Allison, 1989), donation (Van Lange et al., 2007) and negotiation behaviors (De Dreu and Van Lange, 1995) which in turn impact on friendship. For example Majolo et al. (2006) demonstrates a link between cooperation and friendship. Cillessen et al. 
(2005) predict friendship characteristics from prosocial behavior. Further, in social dilemma

studies pro-socials have consistently been found to make more cooperative decisions and to exercise more personal restraint compared to pro-selfs (Liebrand and Van Run 1985, Liebrand, Wilke et al. 1986, Van Lange and Liebrand 1991). Pro-socials are described in the literature as emphasising morality, equality, justice, reciprocity and agreeableness. Pro-selfs on the other hand are described as emphasising might, strength, and intelligence (Liebrand, Jansen et al. 1986, Liebrand, Wilke et al. 1986, Van Lange and Liebrand 1991, Van Lange, De Bruin et al. 1997). Given this we expect to see an association between SVO and friendship.

H5a SVO will be positively related to friendship.

H5b SVO will be positively related to the number of friendship requests made.

H5c SVO will be positively related to the number of friendship invitations received.

Lazarsfeld and Merton (1954) describe value homophily in which friends are similar on a wide variety of internal states, such as SVO, which we test for here.

H6 Users will make friendship links with users who have similar SVO.

\section{Method}

Virtual worlds have been studied with both qualitative (Bainbridge, 2010; Boellstorff, 2008) and quantitative (Chesney et al., 2009) research methods. Here we use a field experiment where participants are introduced to a novel world and their interaction with it and each other is recorded. We have full access to the world's server logs and automatically capture variables not available in a commercial world such as Second Life. This section describes the world, our research participants, how the field study was conducted and then lists the variables that were produced from the server logs. Finally we present our structural model.

\subsection{Data collection}

The virtual world used in this study, Places/Sherwood, was developed by software house Multiverse. The world's aesthetic is modern day Manhattan and its main area is a recreation of Times Square where each avatar has their own private apartment. The world allows text 

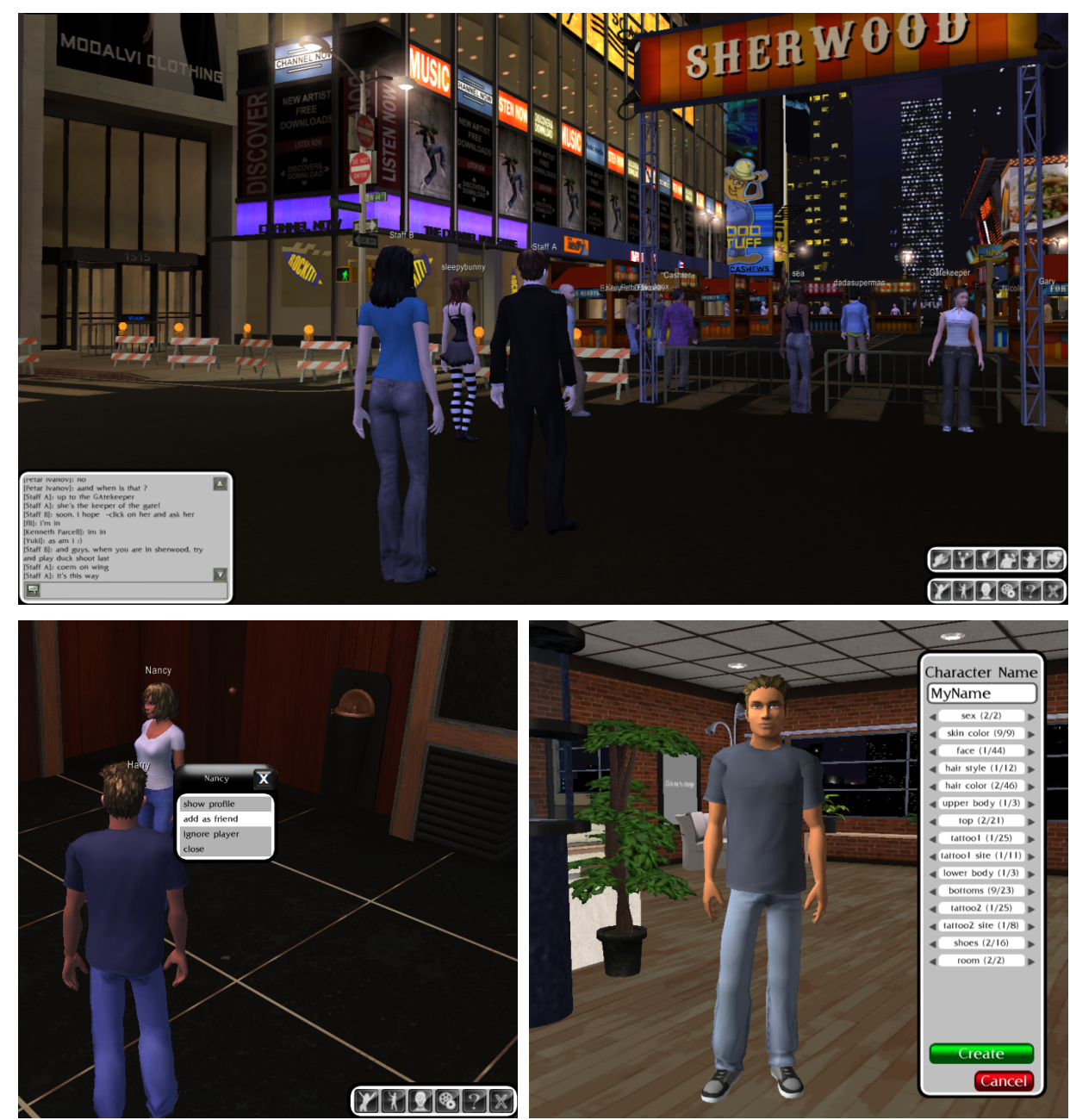

Figure 2: Upper panel: Times Square in Places/Sherwood. Bottom left: inviting an avatar to become a friend. Bottom right: the avatar design interface.

chat and a range of avatar gestures but no audio. Avatars can explore by walking (but not running, jumping or flying) and can invite other avatars to be their friend. For the friendship to form the invited avatar must agree. Friends can communicate privately with each other and can visit each other's apartments. Some of these features are illustrated in Figure 2.

Participants were drawn from a young (ages 18-25) and well-educated (high school or college graduate) population that is known to be computer literate. We used standard recruitment procedures from experimental economics and applied psychology (Kagel and Roth, 1995). To gain access to potential participants we approached groups that were felt likely to have such individuals as members and contacted them through email if this was an option, through posters or by having a member circulate a request for participation. For 
example we approached a role play gaming society and various social clubs. The request included a very brief outline of the study and an email address where people could ask questions and indicate if they would like to become involved.

Those who agreed were randomly assigned to a data collection session in a computer lab. A total of 179 participants took part in one of 20 sessions with between 8 and 12 participants in each. Several days prior to attending the session participants completed an online questionnaire which included information about the study and a question asking for consent to collect survey data. The time lag meant that the questionnaire could not influence behavior.

Participants arrived at the lab at the set time where they were seated randomly and asked to read and sign an informed consent document to cover data collected in the lab. They were then asked to read through a brief user guide of the virtual world they were about to use. If people arrived early they waited in the building's main public thoroughfare. There were no dedicated waiting rooms for participants. Sessions were held in silence with players positioned so that they could not see each other's screens. Participants could therefore see other users in real life but had no way of knowing which user was controlling which avatar. Participants were logged into a fresh account which took them to the avatar creation screen. They could then customize the gender, clothing, hairstyle, hair color and skin color of their avatar.

Avatars initially appeared alone in their apartment where participants could become familiar with the interface controls (on-screen instructions were given). No real world announcements were made after participants were logged in although two researchers were in-world and made announcements from there. Avatars were asked to come to Times Square to explore the world and play an ice-breaker game designed to encourage socialization. The task was based on Schelling's tacit coordination game designed to encourage socialization Schelling (1960). It involved a participant group exploring their mutual virtual environment and jointly nominating a landmark within it to match the choice of another group who faced the same task without the possibility of communication between the two groups. Participants were told that each would receive a reward if the other group nominated the same landmark. This task stimulates perspective taking, that is seeing a situation through some- 
one else's eyes (Krauss and Fussell, 1991) and primes individuals' to perceive making friends as a goal. In turn perspective taking facilitates effective communication, the formation of social bonds and social coordination (Krauss and Fussell, 1991; Galinsky et al., 2005). The reason is that social coordination and harmonious interactions require that a decision maker is able to predict others based on what they know, want and believe. Social coordination involves establishing a common ground of mutual knowledge which this task was intended to promote.

Participants stayed in the virtual world for about 90 minutes. Sessions took place in two physical locations, the UK and Dubai. Participants were paid 5 GBP (or the UAE Dirham equivalent) for attending. Of the 179 participants 104 took part in the UK, 75 in Dubai; 98 were male, 81 female. The average age of participants was 21 . Almost $70 \%$ had used a virtual world before. The world had a help system and additional help was offered in the world by the two researchers.

Note that avatars only had the opportunity to make friends with the others in their session meaning the dataset contains 1806 pairs rather than all 31,862 possible permutations. In 624 of the pairs a friendship request was either given or accepted, in 1182 it was not. The size of each session (8 to 12 participants) was used in our analysis of homophily. The time spent in world and the number of participants means that all possible micro-encounters had ample opportunity to occur. We are confident that all participants observed each other and had opportunity to meet with all other participants in their session, something that we could not say if the sessions had been bigger. Therefore we can capture not only who each participant made friends with but also who they did not make friends with.

\subsection{Variables}

The appendix shows how variables were captured and coded. In this section variable names are given in italics. Following Van Lange et al. (1997b) we operationalize SVO by an individual's preference about how to allocate resources (money) between themselves and another person using a standard questionnaire. This gives the four category classification described earlier with individuals classed using three dummy variables: prosocial, competitive and individualistic. If the individual was none of these each of the three would have the value 
0. Personality was measured using questions from Gosling et al. (2003) which give an ordinal value from low exhibition of the trait (0) to high (4) for each of the traits agreeableness, conscientiousness, extraversion, neuroticism and openness. The number of friends users made, the number of friend requests each user gave out and the number of friend invitations each user received were extracted from the world's server log. How these variables relate is shown in the structural model in Figure 3.

\subsubsection{Controls}

Selfhout et al. (2007) demonstrate that homophily is moderated by gender: similarity plays a larger role in friendships between girls than between boys. We therefore controlled for user gender with a dummy variable (male:1, female:0). Cultural background and ethnicity have also been found to have a huge influence on an individual's value system and choice of friends (Quyen and Zaharim, 2012; Ji et al., 2010) and so we controlled for ethnicity with four dummy variables: Asian, Caucasian, Indian and other. These were derived from a question asking participants to select their ethnicity from a list which was later collapsed into the four used here. Urbanness and attitude to open spaces are known to have an impact on friendships (Seeland et al., 2009; Watters, 2004) and we included a control for this called community, an ordinal value representing how urban a respondent's background is (rural:1 to urban:3). McPherson et al. (2001) suggest wealth homophily and so we control for family income, again with an ordinal measure (low:1 to high:5). The questions used to capture these control variables are shown in the appendix. McPherson et al. (2001) also suggest that age and education will have an impact but these vary little among our participants as explained earlier in this section.

We controlled for the number of participants in the session, session size as it may have an impact: if more people are present there is opportunity to make more friends. Alternatively if fewer people are present then there is less choice in who can be befriended.

When examining the role of SVO we controlled for a possible priming effect through avatar appearance, specifically avatar gender, clothing, hairstyle, presence of tattoos and skin color. Avatar gender is a dummy variable, coded the same as user gender. Avatar clothing options are coded as one of three classifications for avatar top (from the waist up) 

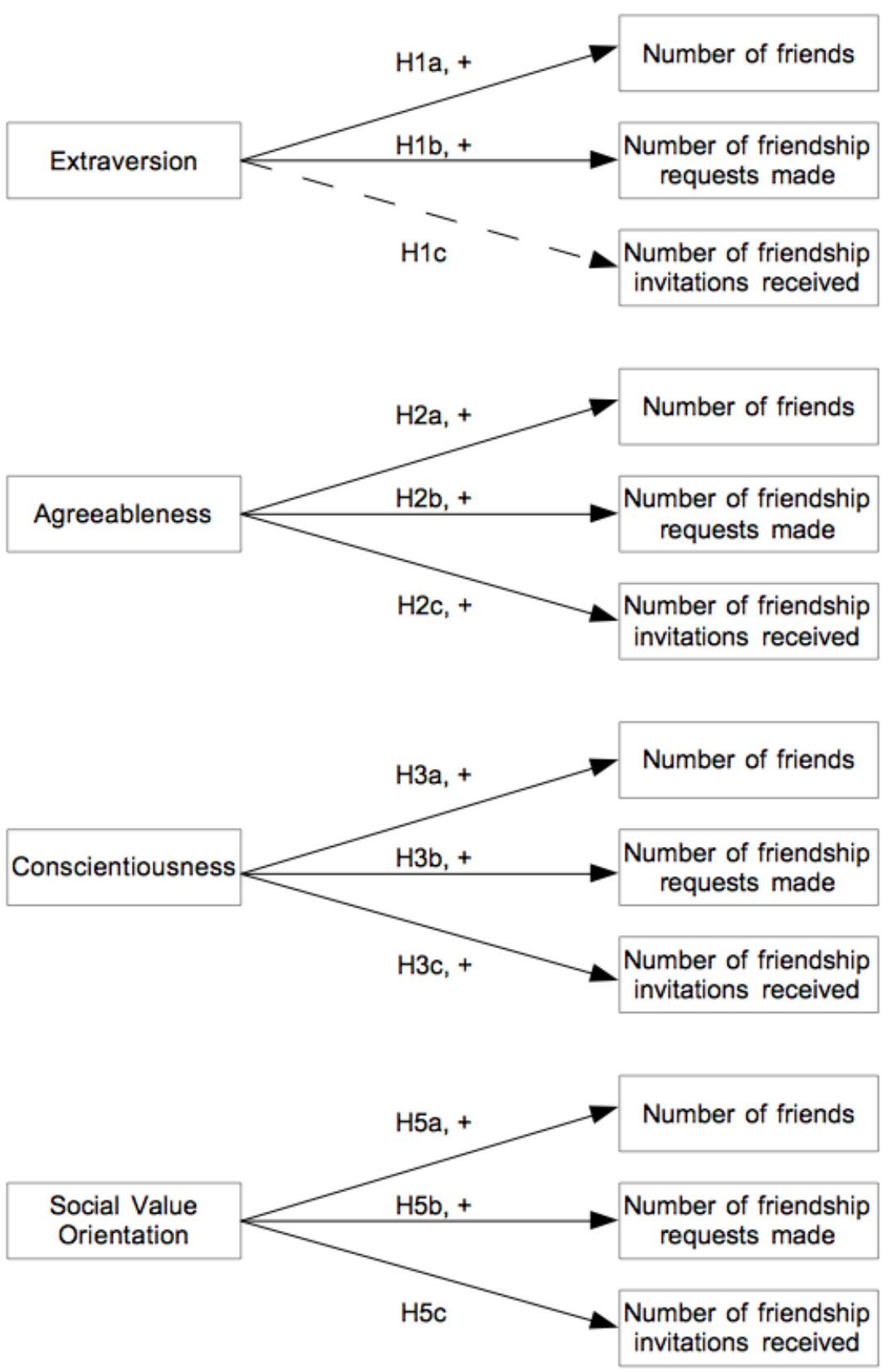

Figure 3: Structural model illustrating Hypotheses 1, 2, 3 and 5. (Hypotheses 4 and 6 relate to a homophily between variables themselves rather than between independent variables and dependent variables, and are therefore not shown here.) Solid lines show a positive association, the dashed line shows no association. 
and bottom (from the waist down). The three classifications represent the amount of skin the clothing reveals and form an ordinal scale from mostly skin (1) to medium skin (2) to covered (3). Amount of skin revealed was chosen as the salient measure of clothing style following previous research (Grammer et al., 2004; Abbey et al., 1987; Rosenfeld and Plax, 1977). It is not the only way clothing options could have been coded but it is universally meaningful unlike certain fashions that mean something particular to certain groups (such as a teenager's attitude to black clothing). Hairstyle was coded on the ordinal scale short (1), medium length (2) and long (3). Tattoo is a dummy variable and indicates the presence of at least one avatar tattoo. Users had nine choices of skin color for their avatar. These represent ordinal data and were merged into two categories, pale (1) and dark (2). Further detail is given in the appendix.

We also extracted several variables from the server log about the chat and movement of avatars including how much an avatar moves about, how close an avatar stands to other avatars, how many words an avatar 'spoke', the length of an avatar's messages and a content analysis of an avatar's chat (see appendix).

\section{Analyses and results}

We ran a series of regressions on our dependent variables (number of friendships, number

of friendship requests and number of friendship invitations) to test Hypotheses 1,2,3 and 5, which are presented next. To examine Hypotheses 4 and 6 which relate to homophily we created a dataset of relationships and ran a linear mixed model. Table 1 shows summary statistics about the SVO, personality and friend making behavior of our participants. Table 2 summarizes our main results. 


\begin{tabular}{rc}
\hline & $\mathrm{n}$ \\
Pro-socials & 66 \\
Individualists & 58 \\
Competitors & 12 \\
\cline { 2 - 2 } & average (sd) \\
Agreeableness & $1.80(0.92)$ \\
Conscientiousness & $2.18(0.96)$ \\
Extraversion & $2.01(0.86)$ \\
Neuroticism & $1.93(0.97)$ \\
Openness & $1.90(0.85)$ \\
Number of friends & $3.07(1.70)$ \\
Number of friend requests & $2.74(2.85)$ \\
Number of friend invitations & $2.85(1.80)$ \\
\hline
\end{tabular}

Table 1: Participant summary statistics. Thirty four participants did not fit into any SVO category, 12 did not respond to this section of the questionnaire. The scale for personality runs from 0 to 4 .

\begin{tabular}{|c|c|c|}
\hline \multicolumn{2}{|c|}{ Hypothesis } & \multirow{2}{*}{$\begin{array}{l}\text { Finding } \\
\text { not supported }\end{array}$} \\
\hline H1a: & extraversion will be positively related to friendship & \\
\hline H1b: & $\begin{array}{l}\text { extraversion will be positively related to the number of } \\
\text { friendship requests }\end{array}$ & not supported \\
\hline H1c: & $\begin{array}{l}\text { extraversion will not be related to friendship invitations } \\
\text { received }\end{array}$ & $\begin{array}{l}\text { no evidence of an } \\
\text { association found }\end{array}$ \\
\hline H2a: & agreeableness will be positively related to friendship & not supported \\
\hline $\mathrm{H} 2 \mathrm{~b}$ : & $\begin{array}{l}\text { agreeableness will be positively related to the number of } \\
\text { friendship requests }\end{array}$ & supported \\
\hline H2c: & $\begin{array}{l}\text { agreeableness will be positively related to the number of } \\
\text { friendship invitations }\end{array}$ & not supported \\
\hline H3a: & conscientiousness will be positively related to friendship & not supported \\
\hline H3b: & $\begin{array}{l}\text { conscientiousness will be positively related to the num- } \\
\text { ber of friendship requests }\end{array}$ & supported \\
\hline H3c: & $\begin{array}{l}\text { conscientiousness will be positively related to the num- } \\
\text { ber of friendship invitations }\end{array}$ & not supported \\
\hline H4: & $\begin{array}{l}\text { users will create friendship links with users who have } \\
\text { similar personality traits }\end{array}$ & partially supported \\
\hline H5a: & SVO will be positively related to friendship & supported \\
\hline H5b: & $\begin{array}{l}\text { SVO will be positively related to the number of friend- } \\
\text { ship requests }\end{array}$ & supported \\
\hline H5c: & $\begin{array}{l}\text { SVO will be positively related to the number of friend- } \\
\text { ship invitations }\end{array}$ & not supported \\
\hline H6: & $\begin{array}{l}\text { users will create friendship links with users who have } \\
\text { similar SVO }\end{array}$ & not supported \\
\hline
\end{tabular}

Table 2: Summary of main results. 


\subsection{Number of friends}

Results of regressing on the number of friendships made are shown in Table 3. Hypotheses relating personality to number of friends (H1a, H2a, H3a) were not supported. We did find support for a relationship between SVO and number of friends (H5a): the individualistic social value is positively related to the number of friends made. Individualists made 0.78 more friends than others. We examined the result the personality trait openness further as it is close to being significant (in line with a recommendation by Cumming (2011)). To do this we ran the regression again removing the avatar design variables (which were included as controls for their impact on SVO and not on personality, as explained in Section 3.2.1). The results are presented in Table 4 and show that openness is positively related to number of friends made, a finding that was not hypothesised: for every one unit increase in openness individuals make 0.36 more friends. Session size is significantly and negatively related to number of friends suggesting that session size has an impact through increasing interactions when the fewer people are present (Table 3). This same effect is seen in all of our results albeit not always significant. 


\begin{tabular}{rrrrrl}
\hline & estimate & std. error & t-value & p-value & \\
\hline Agreeableness & -0.14 & 0.16 & -0.84 & 0.401 & \\
Conscientiousness & 0.23 & 0.17 & 1.38 & 0.171 & \\
Extraversion & -0.06 & 0.18 & -0.33 & 0.741 & \\
Neuroticism & -0.04 & 0.17 & -0.20 & 0.838 & \\
Openness & 0.33 & 0.20 & 1.66 & 0.100 & \\
\hline Prosocial & -0.04 & 0.41 & -0.11 & 0.915 & \\
Individualistic & 0.78 & 0.40 & 1.97 & 0.051 & $*$ \\
Competitive & 0.48 & 0.63 & 0.77 & 0.445 & \\
\hline Asian & 0.04 & 0.38 & 0.11 & 0.914 & \\
Caucasian & 0.30 & 0.47 & 0.64 & 0.523 & \\
Indian & -0.29 & 0.41 & -0.70 & 0.486 & \\
Other ethnicity & 0.32 & 0.50 & 0.63 & 0.532 & \\
Community & 0.05 & 0.15 & 0.31 & 0.757 & \\
Family income & 0.11 & 0.09 & 1.16 & 0.247 & \\
User gender & 0.36 & 0.41 & 0.88 & 0.379 & \\
Session size & -0.13 & 0.06 & -2.26 & 0.025 & $* *$ \\
Avatar skin color & -0.02 & 0.36 & -0.07 & 0.945 & \\
Avatar hairstyle & 0.08 & 0.23 & 0.36 & 0.717 & \\
Avatar top & -0.77 & 0.33 & -2.31 & 0.023 & $* *$ \\
Avatar bottom & -0.48 & 0.27 & -1.79 & 0.075 & $*$ \\
Avatar tattoo & -0.19 & 0.37 & -0.51 & 0.611 & \\
\hline
\end{tabular}

Table 3: Regressing number of friends. $n=142, R^{2}=0.13$, sig.codes $: * * *=1 \%, * *=5 \%, *=10 \%$

\begin{tabular}{rrrrrr}
\hline & estimate & std. error & t-value & p-value & \\
\hline Agreeableness & -0.17 & 0.17 & -1.05 & 0.295 & \\
Conscientiousness & 0.19 & 0.17 & 1.11 & 0.268 & \\
Extraversion & 0.02 & 0.18 & 0.08 & 0.933 & \\
Neuroticism & -0.01 & 0.18 & -0.05 & 0.957 & \\
Openness & 0.36 & 0.205 & 1.75 & 0.082 & $*$ \\
\hline Prosocial & 0.00 & 0.41 & 0.00 & 0.996 & \\
Individualistic & 0.74 & 0.41 & 1.80 & 0.074 & $*$ \\
Competitive & 0.71 & 0.64 & 1.10 & 0.272 & \\
\hline Asian & -0.09 & 0.39 & -0.24 & 0.811 & \\
Caucasian & 0.25 & 0.46 & 0.53 & 0.597 & \\
Indian & -0.42 & 0.43 & -1.02 & 0.311 & \\
Other ethnicity & 0.37 & 0.50 & 0.74 & 0.459 & \\
Community & 0.13 & 0.14 & 0.88 & 0.379 & \\
Family income & 0.05 & 0.09 & 0.57 & 0.567 & \\
User gender & -0.21 & 0.32 & -0.65 & 0.520 & \\
Session size & -0.12 & 0.06 & -2.04 & 0.043 & $* *$ \\
\hline
\end{tabular}

Table 4: Regressing number of friends without controls for avatar appearance. $n=142, R^{2}=0.06$, sig.codes : $* * *=1 \%, * *=5 \%, *=10 \%$ 


\subsection{Number of friendship requests}

Results of regressing on the number of friendship requests are shown in Table 5. Agreeableness and the individualistic social value are both positively related to the number of friendship requests given out, supporting $\mathrm{H} 2 \mathrm{~b}$ and $\mathrm{H} 5 \mathrm{~b}$. For every one unit increase in agreeableness a user makes 0.47 more friend requests. Individualists make 1.79 more friendship requests than others. This time the result on conscientiousness was studied further. The results are set out in Table 6 and show that conscientiousness is also positively related to the number of friendship requests given out, offering support for H3b. For every one unit increase in conscientiousness and individual makes about 0.5 more friendship requests. Extraversion was not related to number of friends made or number of friendship requests given out, H1b.

\begin{tabular}{rrrrrr}
\hline & estimate & std. error & t value & p-value & \\
\hline Agreeableness & 0.47 & 0.267 & 1.76 & 0.080 & $*$ \\
Conscientiousness & 0.41 & 0.26 & 1.58 & 0.116 & \\
Extraversion & 0.26 & 0.30 & 0.85 & 0.40 & \\
Neuroticism & -0.02 & 0.28 & -0.07 & 0.946 & \\
Openness & -0.03 & 0.33 & -0.09 & 0.930 & \\
\hline Prosocial & 0.40 & 0.65 & 0.61 & 0.542 & \\
Individualistic & 1.79 & 0.65 & 2.74 & 0.007 & $* * *$ \\
Competitive & 1.17 & 1.16 & 1.00 & 0.317 & \\
\hline Asian & 0.85 & 0.61 & 1.39 & 0.168 & \\
Caucasian & 0.49 & 0.70 & 0.71 & 0.480 & \\
Indian & 0.40 & 0.64 & 0.62 & 0.534 & \\
Other ethnicity & 0.08 & 0.77 & 0.11 & 0.913 & \\
Community & -0.26 & 0.23 & -1.13 & 0.260 & \\
Family income & 0.15 & 0.15 & 1.01 & 0.316 & \\
User gender & 0.95 & 0.66 & 1.43 & 0.154 & \\
Session size & -0.15 & 0.09 & -1.62 & 0.108 & \\
Avatar skin color & -0.07 & 0.59 & -0.12 & 0.903 & \\
Avatar hairstyle & -0.42 & 0.36 & -1.15 & 0.251 & \\
Avatar top & -0.64 & 0.51 & -1.25 & 0.212 & \\
Avatar bottom & -1.07 & 0.41 & -2.62 & 0.010 & $* * *$ \\
Avatar tattoo & 0.38 & 0.58 & 0.65 & 0.515 & \\
\hline
\end{tabular}

Table 5: Regressing number of friendship requests a user sends out. $n=149, R^{2}=0.11$, sig.codes $: * * *=$ $1 \%, * *=5 \%, *=10 \%$ 


\begin{tabular}{rrrrrr}
\hline & estimate & std. error & t-value & p-value & \\
\hline Agreeableness & 0.39 & 0.27 & 1.46 & 0.147 & \\
Conscientiousness & 0.45 & 0.27 & 1.70 & 0.091 & $*$ \\
Extraversion & 0.39 & 0.31 & 1.28 & 0.203 & \\
Neuroticism & -0.00 & 0.28 & -0.02 & 0.99 & \\
Openness & -0.06 & 0.34 & -0.16 & 0.870 & \\
\hline Prosocial & 0.36 & 0.66 & 0.55 & 0.581 & \\
Individualistic & 1.70 & 0.67 & 2.54 & 0.012 & $* *$ \\
Competitive & 1.44 & 1.18 & 1.22 & 0.224 & \\
\hline Asian & 0.65 & 0.62 & 1.05 & 0.30 & \\
Caucasian & 0.23 & 0.69 & 0.33 & 0.739 & \\
Indian & -0.02 & 0.64 & -0.03 & 0.98 & \\
Other ethnicity & -0.01 & 0.78 & -0.02 & 0.987 & \\
Community & -0.19 & 0.23 & -0.81 & 0.420 & \\
Family income & 0.10 & 0.15 & 0.66 & 0.509 & \\
User gender & 0.74 & 0.51 & 1.46 & 0.147 & \\
Session size & -0.15 & 0.09 & -1.62 & 0.108 & \\
\hline
\end{tabular}

Table 6: Regressing number of friendship requests a user sends out without controls for avatar appearance. $n=149, R^{2}=0.06$, sig.codes $: * * *=1 \%, * *=5 \%, *=10 \%$ 


\subsection{Number of friendship invitations}

Table 7 shows the results of regressing on the number of friendship invitations users receive. Neither personality nor SVO, or any of the control variables were related to the number of friendship invitations a user receives, giving no support for H1c, H2c, H3c and H5c.

\begin{tabular}{rrrrr}
\hline & estimate & std. error & t-value & p-value \\
\hline Agreeableness & -0.16 & 0.17 & -0.97 & 0.332 \\
Conscientiousness & 0.19 & 0.17 & 1.14 & 0.256 \\
Extraversion & -0.07 & 0.19 & -0.39 & 0.696 \\
Neuroticism & -0.15 & 0.18 & -0.88 & 0.381 \\
Openness & -0.09 & 0.20 & -0.45 & 0.652 \\
\hline Prosocial & -0.27 & 0.41 & -0.66 & 0.511 \\
Individualistic & 0.54 & 0.41 & 1.32 & 0.189 \\
Competitive & -0.04 & 0.68 & -0.06 & 0.951 \\
\hline Asian & -0.10 & 0.38 & -0.27 & 0.789 \\
Caucasian & -0.32 & 0.45 & -0.71 & 0.480 \\
Indian & -0.24 & 0.40 & -0.60 & 0.551 \\
Other ethnicity & -0.57 & 0.47 & -1.21 & 0.228 \\
Community & 0.08 & 0.15 & 0.54 & 0.592 \\
Family income & 0.04 & 0.10 & 0.45 & 0.653 \\
User gender & -0.66 & 0.41 & -1.58 & 0.116 \\
Session size & -0.03 & 0.06 & -0.50 & 0.615 \\
Avatar skin colour & -0.36 & 0.37 & -0.97 & 0.331 \\
Avatar hairstyle & 0.15 & 0.23 & 0.65 & 0.515 \\
Avatar top & 0.18 & 0.34 & 0.54 & 0.589 \\
Avatar bottom & 0.12 & 0.27 & 0.45 & 0.655 \\
Avatar tattoo & -0.21 & 0.36 & -0.59 & 0.559 \\
\hline
\end{tabular}

Table 7: Regressing number of friendship invitations a user receives. $n=165, R^{2}=0.01$, sig.codes $: * * *=$ $1 \%, * *=5 \%, *=10 \%$ 


\subsection{Homophily}

To test for homophily (H4 and $\mathrm{H} 6$ ) a dataset was created that included pairs of users that formed friendships with each other and pairs that did not form friendships as illustrated in Figure 4. The dataset included all possible pairs. Friendship, a binary variable, was regressed against the personality and SVO variables recoded as dummies to indicate whether a match occurred between User 1 and User 2 in the value of the variable. The results are shown in Table 8. A linear mixed model was used as the rows in the dataset described in Figure 4 are not strictly independent of each other and therefore break an assumption of the logit regression. The mixed model overcomes this problem by clustering the data in a way that maintains independence, in this case clustering by User 1. No support is found for H6 and only partial support is found for H4. The model shows that conscientiousness is homophilious: users tended to make avatar-mediated friendships with other users who have similar conscientiousness as they do. The model also suggests that family income and avatar clothing are heterophilious. Users tended to form avatar-mediated friendships with other users who have different income levels, and whose avatars dress differently from their own avatar.

\subsection{SVO, personality and virtual world behavior}

The results presented in Section 4.3 could be explained if a user's personality and SVO simply could not be perceived through an avatar as discussed in Section 2.3. To confirm that they can potentially be perceived and examine the mechanism by which this may happen we tested for links between avatar behavior and SVO as well as personality traits with the following regression model (shown in long hand):

$V W \_$behavior $=$agreeableness + conscientiousness + extraversion + neuroticism + openness + prosocial + individualistic + competitive + controls

We examined the following virtual world behaviors: avatar design, chat and movement (the variables are explained in Section 3.1 and the appendix). We found significant differences in all three aspects of virtual world behavior supporting the notion that both personality and SVO have an impact on virtual world behavior and therefore that signals of both can be seen in the appearance, chat and movement of avatars: 
- Extraverts' avatars' clothing showed significantly more skin (although this effect disappeared when controlling for ethnicity) and sported more tattoos. The avatars of those with competitive SVO tended to show more skin than other avatars, although very few of our participants had a competitive SVO.

- Extraverts made fewer movements, individualists made more movements. Users with high openness kept their avatar closer to other avatars.

- Both extraverts and neurotics used a lower percentage of one word sentences. Neurotics made fewer positive comments. Those with high agreeableness made fewer neutral comments, those with high openness made more neutral comments. (There was no difference in the number of negative remarks made).

That we observed significant differences means that theoretically a user could perceive and make judgements about another user's personality and SVO.

\begin{tabular}{llllll}
\hline Avatar 1 & Avatar 2 & Friendship & User 1 & User 2 & Match \\
characteristics & characteristics & variables \\
\hline AA & BB & 1 & $\ldots$ & $\ldots$ & $\ldots$ \\
BB & AA & 1 & $\ldots$ & $\ldots$ & $\ldots$ \\
AA & CC & 1 & $\ldots$ & $\ldots$ & $\ldots$ \\
CC & AA & 0 & $\ldots$ & $\ldots$ & $\ldots$ \\
AA & DD & 0 & $\ldots$ & $\ldots$ &
\end{tabular}

Figure 4: Illustration of the structure of the dataset used to examine for homophily. Avatar AA asked BB to be their friend (Row 1) and they agreed (Row 2). AA asked CC to be their friend (Row 3) but they did not agree (Row 4). AA did not ask DD to be their friend (Row 5). All other possible combinations of avatar pairs would appear in later rows. User characteristics are taken from the questionnaire. Match variables were used in examining for homophily and record whether a match exists between a User 1 characteristic and a User 2 characteristic. 


\begin{tabular}{rccccc}
\hline & estimate & std. error & t-value & p-value & \\
\hline Agreeableness match & 0.10 & 0.12 & 0.80 & 0.424 & \\
Conscientiousness match & 0.23 & 0.11 & 1.97 & 0.049 & $* *$ \\
Extraversion match & -0.19 & 0.12 & -1.56 & 0.118 & \\
Neuroticism match & -0.09 & 0.12 & -0.75 & 0.452 & \\
Openness match & 0.00 & 0.12 & 0.01 & 0.992 & \\
SVO match & 0.12 & 0.12 & 0.97 & 0.333 & \\
Ethnicity match & 0.09 & 0.13 & 0.75 & 0.455 & \\
Community match & -0.05 & 0.12 & -0.47 & 0.641 & \\
Family income match & -0.24 & 0.13 & -1.90 & 0.058 & $*$ \\
User gender match & 0.25 & 0.14 & 1.84 & 0.067 & $*$ \\
Avatar gender match & 0.01 & 0.15 & 0.10 & 0.919 & \\
Avatar top match & -0.40 & 0.13 & -3.12 & 0.002 & $* * *$ \\
Avatar bottom match & -0.25 & 0.13 & -1.92 & 0.055 & $*$ \\
Avatar tattoo match & 0.00 & 0.12 & 0.02 & 0.984 & \\
Avatar skin color match & -0.00 & 0.13 & -0.01 & 0.995 & \\
Avatar hairstyle match & 0.09 & 0.12 & 0.77 & 0.442 & \\
\hline
\end{tabular}

Table 8: Model to test for homophily, regressing friendship on the match variables. observations $=$ 1806, groups $=179$, sig.codes $: * * *=1 \%, * *=5 \%, *=10 \%$ 


\section{Discussion}

This final section reviews our work. We begin with a summary before highlighting the main findings. Their implications and relevance are then discussed along with suggestions for further research.

In this paper we examined how user personality and social value orientation influence the avatar-mediated friendships that form inside a virtual world. We focused on the context of micro-encounters between two people who have just met and are unaware of the other's real identity. We analysed the number of friendships made, the number of attempts to make friends, the number of times a user was selected for friendship and the existence of user-user homophily. We also looked at whether signals of a user's personality and SVO are transmitted through their avatar. We have a good sample size and rich data were obtained from the server logs. Our datasets include information on who made friends with whom plus information on potential friendships that did not form. All personality traits and social values are well represented in our data with the exception of highly competitive values.

While we did not find evidence that personality differences lead to more friendships we did find that social values have an impact: individualists make more friends. The likely reason is that individualists see friendship as intrinsically valuable to them and thus desirable. We found evidence that certain aspects of both personality and SVO impact on the number of friendship requests a user makes: users who are agreeable and conscientious issue more invitations of friendship, as do users with individualistic values.

In terms of friendship invitations received, we found that personality and SVO have no impact. To explain this, we contrast our three dependent variables. Number of friendships formed and number of friendships requests sent out are solely or in part attributable to a user; however the invitations received by a user are entirely attributable to other users. The fact that we found no significant explanators for invitations received could be because personality and SVO signals are not being transmitted through an avatar and therefore are not being perceived by other users. We investigated this and found evidence that users' personality and SVO do in fact relate to differences observed in their virtual world behavior in terms of avatar design, chat and movement. We conclude therefore that personality and SVO moderate avatar behavior but not so to influence friendship invitations received. 
We found little evidence of homophily. The model shows that conscientiousness is homophilious: users tended to make avatar-mediated friendships with users who have similar conscientiousness. The model also suggests that family income and avatar clothing are heterophilious: users tended to form friendships with users who have different income levels, and whose avatars dress differently from their own. This result is interesting and suggests that social factors (rather than intra-personal psychological ones) may shape interactions. Future work could usefully examine the relationship between social and psychological factors in determining virtual world behaviour.

While real world research suggests that extraversion impacts friendship, we found no evidence of this here. The reason may be the levelling effect identified in previous research (see Section 2) that means avatars with similar attractiveness tend to cause users low on extraversion to behave more extraverted. ${ }^{2}$ The lack of a significant association in regards to extraversion and other personality dimensions goes against what is known about real world associations but is in line with the idea that interaction mediated through an avatar changes a user's behavior.

Session size had a negative effect on the number of friends made. As seen in Tables 3-6, for every one additional person in the virtual world users made about 0.1 fewer friends. There could be a 'rabbit-caught-in-the-headlights' effect where a higher choice of potential friends actually makes it more difficult to find friends in a virtual world. Again future work should examine this.

Our results have relevance for the design and deployment of virtual worlds in both entertainment and education. It is in this latter area where particularly important implications arise. Social learning theories highlight several ways in which social interaction with other learners aid a person's learning. One way is through observation and emulation of others. Another is positive reinforcement from others. Both depend on sufficiently close relationships with others. Developers of educational virtual worlds could potentially draw on this result to help design worlds with a view to facilitating social interactions. For example our findings suggest that user values are more important in determining virtual world relation-

\footnotetext{
${ }^{2}$ Our avatars had identical levels of beauty to the extent that the same face was used both by all males and females respectively. Only the avatar appearance variables outlined in Section 3.2.1 could be changed.
} 
ships than personality. Some educators already use personality tests. Extending this with suitable measures of values, worlds could be programmed to bring together individuals who are likely to socialize, in a similar way to how Facebook and other social media suggest 'people you may know'.

This paper adds to a growing literature that is finding key differences between virtual world and real world relationships. Further work to examine our findings in different contexts is warranted. Our results were generated in an environment with interactions lasting a fixed period. It would be desirable to test their robustness longitudinally in worlds where interactions unfold over longer time periods. It may also be useful to contrast our findings with relationships from other online environments such as open source software development communities which also entail shared activity.

\section{Appendix A. Capturing and coding the variables}

The following variables were captured by the questionnaire: personality, social values orientation, sex, age, ethnicity, income and community. The following variables were captured by the virtual world's server logs: avatar appearance, avatar movement, friendships made, number of friendship requests sent and received.

As mentioned in the text, personality was measured using questions from Gosling et al. (2003), which is an approach recommended when a brief measure is needed. (The reason a brief measure was necessary is that the full questionnaire for the larger project of which this study is a part was considerably lengthy and hence there was a risk of paricipant fatigue). Social value orientation was measured with questions from Van Lange et al. (1997b).

The number of friends made, the number of friendship requests each user gave out and the number of friendship invitations each user received were extracted from the world's server $\log$.

Income was measured with the following question: to which income group does your family belong? Participants could select one answer from choices grouped in 5 categories of the population, going from the lowest $20 \%$ coded as 1, to the highest $20 \%$ coded as 5 .

Ethnicity was coded into one of Asian, Caucasian, Indian and Other. These ethnicities were decided solely on the frequency of the demographics of our participants. Ethnicity was 
measured with the following question: what is your ethnic background?

To measure Community participants were shown three options and asked which best describes the community in which they grew up: rural coded as 1, suburban 2, and urban coded as 3 .

Avatar variables were extracted from the world's server logs. The classification of avatar clothing, hair and skin variables was done independently by two observers with excellent overall inter-rater agreement.

The following were discussed and used in Section 4.1:

For movement metrics we counted the number of moves avatars made in any direction (the possible moves were forward, backward, turn left, turn right, step left and step right). We also measured the average distance an avatar stayed from the next closest avatar.

To analyse avatar chat, a content analysis was carried out independently by one researcher who was not involved in the data collection. The data were coded according to guidelines provided by Elo and Kyngas (2008). Code classifications were made and then a subset (500 messages, which is roughly $7 \%$ of the total) of the chat was independently classified by a second researcher. When the classifications of each sentence were examined for inter-rater reliability, there was $76.7 \%$ agreement between the two. The agreement expected by chance was $7.6 \%$ and Cohens kappa was calculated to be 0.748 , which indicates a good level of agreement (Landis and Koch, 1977). One of the classifications concerned personal remarks made about other avatars. We counted the number of positive, negative and neutral remarks made. We also counted the number of words avatar's spoke per message. 


\section{ACKNOWLEDGEMENTS}

This research formed part of the VERUS project, led by John Murray at SRI International, and was funded by the U.S. Air Force Research Lab under contract number FA865010-C-7009. The authors thank Don Arns, Steve Benford, John Byrnes, Kyle Leveque, Immanuel Moonesar, Said Muhammad, Wen Wang, and the University of Wollongong, Dubai, for their help, and acknowledge research assistance from Natasha Ambigaibalan, Kasia Cambell and Lu Dong.

\section{References}

Aas, G., Meyerbröker, K., Emmelkamp, P., 2010. Who am i - and if so, where? a study on personality in virtual realities. Journal of Virtual Worlds Research 2 (5).

Abbey, A., Cozzarelli, C., McLaughlin, K., Harnish, R. J., 1987. The effects of clothing and dyad sex composition on perceptions of sexual intent: Do women and men evaluate these cues differently. Journal of Applied Social Psychology 17 (2), 108-126.

Agarwal, R., Gupta, A. K., Kraut, R., 2008. The interplay between digital and social networks. Information Systems Research 19 (3), $243-252$.

Ahuja, G., Polidoro, F., Mitchell, W., 2009. Structural homophily or social asymmetry? the formation of alliances by poorly embedded firms. Strategic Management Journal 30, 941-958.

Ahuja, G., Soda, G., Zaheer, A., 2012. The genesis and dynamics of organizational networks. Organization Science 23 (2), 434-448.

Amichai-Hamburger, Y., 2002. Internet and personality. Computers in Human Behavior 18 (1), 1 - 10.

Amichai-Hamburger, Y., Kaplan, H., Dorpatcheon, N., 2008. Click to the past: The impact of extroversion by users of nostalgic websites on the use of internet social services. Computers in Human Behavior $24(5), 1907-1912$.

Back, M. D., Schmukle, S. C., Egloff, B., 2008. How extraverted is honey.bunny77@hotmail.de? inferring personality from e-mail addresses. Journal of Research in Personality 42 (4), 1116-1122.

Bagozzi, R. P., Dholakia, U. M., 2006. Open source software user communities: A study of participation in linux user groups. Management Science 52 (7), 1099-1115.

Bainbridge, W. S., 2010. The Warcraft Civilization. MIT Press.

Balliet, D., Parks, C., Joireman, J., 2009. Social value orientation and cooperation in social dilemmas: A meta-analysis. Group Processes \& Intergroup Relations 12 (4), 533-547.

Bardi, A., Schwartz, S., 2003. Values and behavior: Strength and structure of relations. Personality and Social Psychology Bulletin 29 (10), 1207-1220. 
Barney, D., 2004. Community in the digital age: Philosophy and practice. Rowman and Littlefield, Ch. The vanishing table, or community in a world that is no world, pp. 31-52.

Barrick, M. R., Mount, M. K., Judge, T. A., 2001. Personality and performance at the beginning of the new millennium: What do we know and where do we go next? International Journal of Selection and Assessment 9 (1-2), 9-30.

Beggan, J., Messick, D., Allison, S., 1988. Social values and egocentric bias: two tests of the "might over morality" hypothesis. Journal of Personality and Social Psychology 55, 606-611.

Bell, M., 2008. Toward a definition of "virtual worlds". Journal of Virtual Worlds Research 1 (1).

Benford, S., Greenhalgh, C., Rodden, T., Pycock, J., Jul. 2001. Collaborative virtual environments. Communications of the ACM 44 (7), 79-85.

Bessière, K., Seay, A., Kiesler, S., 2007. The ideal elf: identity exploration in world of warcraft. Cyberpsychology and Behaviour 10 (4), 530-535.

Boellstorff, T., 2008. Coming of age in Second Life. Princeton University Press.

Bohannon, J., 2010. Smarts for serious games. Science 330 (6000), 31.

Borgmann, A., 2004. Community in the digital age: Philosophy and practice. Rowman and Littlefield, Ch. Is the Internet the solution to the problem of community?, pp. 53-68.

Briggle, A., 2008. Real friends: how the internet can foster friendship. Ethics and Information Technology $10(1), 71-79$.

Byrne, D., 1971. The Attraction Paradigm. Academic Press.

Carley, K., 1991. A theory of group stability. American Sociological Review 56, 331-354.

Chesney, T., Chuah, S., Hoffmann, R., 2009. Virtual world experimentation: an exploratory study. Journal of Economic Behavior \& Organization 72 (1), 618-635.

Chesney, T., Chuah, S., Hoffmann, R., Hui, W., Larner, J., 2014. Determinants of friendship in social networking virtual worlds. Communications of the Association for Information Systems 34 (72).

Chuah, S., 2008. Economics and culture : the role of values in shaping experimental behaviour. Ph.D. thesis, Nottinghan University Business School.

Cillessen, A., Jiang, X., West, T., Laszkowski, D., 2005. Predictors of dyadic friendship quality in adolescence. International Journal of Behavioral Development 29 (2), 165-172.

Cocking, D., Matthews, S., 2000. Unreal friends. Ethics and Information Technology 2 (4), 223-231.

Cohen, D. C., Sevdalis, N., Patel, V., Taylor, D., Batrick, N., Darzi, A. W., 2012. Major incident preparation for acute hospitals: Current state-of-the-art, training needs analysis, and the role of novel virtual worlds simulation technologies. The Journal of Emergency Medicine 43 (6), 1029 - 1037.

URL http://www.sciencedirect.com/science/article/pii/S0736467912004234

Collins, R., 2004. Interaction Ritual Chains. Princeton University Press.

Connolly, T. M., Boyle, E. A., MacArthur, E., Hainey, T., Boyle, J. M., 2012. A systematic literature review of empirical evidence on computer games and serious games. Computers \& Education 59 (2), 661 - 
686.

URL http://www.sciencedirect.com/science/article/pii/S0360131512000619

Connor, P., Becker, B., 1994. Personal values and management: What do we know and why don't we know more? Journal of Management Inquiry 3 (1), 67-73.

Costa, P., McCrae, R., 1992. Neo pi-r professional manual. Tech. rep., Psychological Assessment Resources, Inc., Odessa, FL.

Coulson, M., Barnett, J., Ferguson, C. J., Gould, R. L., 2012. Real feelings for virtual people: Emotional attachments and interpersonal attraction in video games. Psychology of Popular Media Culture 1 (3), $176-184$.

Cumming, G., 2011. Understanding the new statistics. Routledge.

de Castell, S., Jenson, J., Taylor, N., Thumlert, K., 2014. Re-thinking foundations: Theoretical and methodological challenges (and opportunities) in virtual worlds research. Journal of Gaming \& Virtual Worlds $6(1), 3-20$.

De Dreu, C., Van Lange, P., 1995. The impact of social value orientations on negotiator cognition and behavior. Personality and Social Psychology Bulletin 21, 1178-1188.

Denissen, J., Penke, L., 2008. Motivational individual reaction norms underlying the five-factor model of personality: First steps towards a theory-based conceptual framework. Journal of Research in Personality $42(5), 1285-1302$.

Denissen, J. J. A., Schönbrodt, F. D., van Zalk, M., Meeus, W. H. J., van Aken, M. A. G., 2011. Antecedents and consequences of peer-rated intelligence. European Journal of Personality 25 (2), 108-119.

Devaraj, S., Easley, R. F., Crant, J. M., 2008. Research note-how does personality matter? relating the five-factor model to technology acceptance and use. Information Systems Research 19 (1), 93-105.

Dieterle, E., Murray, J., 2010. Virtual Environment Real User Study (VERUS): Design and methodological considerations and implications. Journal of Applied Learning Technology 1 (1), 19-25.

Digman, J., 1990. Personality structure: Emergence of the five-factor model. Annual Review of Psychology $41,417-440$.

Digman, J., Inouye, J., 1986. Further specification of the five robust factors of personality. Journal of Personality and Social Psychology 50, 116-123.

Digman, J., Takemoto-Chock, N., 1981. Factors in the natural language of personality: Re-analysis, comparison, and interpretation of six major studies. Multivariate Behavioral Research 16 (2), 149-170.

Ducheneaut, N., Wen, M., Yee, N., Wadley, G., 4-9 April 2009. Body and mind: A study of avatar personalization in three virtual worlds. In: CHI Proceedings. Boston, Massachusetts.

Easley, D., Kleinberg, J., 2010. Networks, Crowds and Markets. Cambridge University Press.

Elo, S., Kyngas, H., 2008. The qualitative content analysis process. Journal of Advanced Nursing 62 (1), $107-115$.

Eysenck, H., 1947. Dimensions of Personality. Transaction Publishers. 
Fleeson, W., Malanos, A., Noelle, M., 2002. An intraindividual process approach to the relationship between extraversion and positive affect: Is acting extraverted as "good" as being extraverted? Journal of Personality and Social Psychology 83 (6), 1409-1422.

Freeman, J., Ambady, N., 2011. A dynamic interactive theory of person construal. Psychological Review $118(2), 247-279$.

Gable, S., Reis, H., Impett, E., Asher, E., 2004. What do you do when things go right? the intrapersonal and interpersonal benefits of shareing positive events. Journal of Personality and Social Psychology $87(2), 34-40$.

Galinsky, A., Ku, G., Wang, C., 2005. Perspective-taking and self-other overlap: Fostering social bonds and facilitating social coordination. Group Processes \& Intergroup Relations 8 (2), 109-124.

Ghanbarzadeh, R., Ghapanchi, A. H., Blumenstein, M., Talaei-Khoei, A., 02 2014. A decade of research on the use of three-dimensional virtual worlds in health care: A systematic literature review. Journal of Medical Internet Research 16 (2), e47.

URL http://www.ncbi.nlm.nih.gov/pmc/articles/PMC3958677/

Gill, A. J., Oberlander, J., Austin, E., 2006. Rating e-mail personality at zero acquaintance. Personality and Individual Differences 40 (3), 497-507.

Goldberg, L., 1993. The structure of phenotypic personality traits. American Psychologist 48 (1), 26-34.

Gosling, S., Ko, S., Mannarelli, T., Morris, M., 2002. A room with a cue: Judgments of personality based on offices and bedrooms. Journal of Personality and Social Psychology 82 (3), 379-398.

Gosling, S. D., Rentfrow, P. J., Swann, W. B., 2003. A very brief measure of the big-five personality domains. Journal of Research in Personality 37, 504-528.

Grammer, K., Renninger, L., Fischer, B., 2004. Disco clothing, female sexual motivation, and relationship status: Is she dressed to impress? Journal of Sex Research 41 (1), 66-74.

Granhag, P., Vrij, A., 2005. Psychology and Law an empirical perspective. Guilford Press, Ch. Deception Detection.

Guadagno, R. E., Okdie, B. M., Eno, C. A., 2008. Who blogs? personality predictors of blogging. Computers in Human Behavior 24 (5), 1993-2004.

Gulati, R., 1995. Social Structure and Alliance Formation Patterns: A Longitudinal Analysis. Administrative Science Quarterly 40 (4), 619-652.

Hinds, P., Carley, K., Krackhardt, D., Wholey, D., 2000. Choosing work group members: balancing similarity, competence and familiarity. Organizational Behavior and Human Decision Processes 81 (2), 226-251.

Hofstede, G., 1994. Cultures and organisations: software of the mind. Harper Collins.

Holmes, J. G., 2002. Interpersonal expectations as the building blocks of social cognition: An interdependence theory perspective. Personal Relationships 9 (1), 1-26.

Hsieh, G., Hou, Y., Chen, I., Truong, K. N., 2013. 'welcome!': social and psychological predictors of volunteer socializers in online communities. In: Bruckman, A., Counts, S., Lampe, C., Terveen, L. G. (Eds.), 
CSCW. ACM, pp. 827-838.

Ibarra, H., 1993. Personal networks of women and minorities in management: a conceptual framework. Academy of Management Review 18, 56-87.

Ingram, P., Morris, M. W., 2007. Do people mix at mixers? structure, homophily, and the "life of the party". Administrative Science Quarterly 52 (4), 558-585.

Iribarren, J., Moro, E., 2011. Affinity paths and information diffusion in social networks. Social Networks $33,134-142$.

Jadin, T., Gnambs, T., Batinic, B., 2013. Personality traits and knowledge sharing in online communities. Computers in Human Behavior 29 (1), 210 - 216.

Jensen-Campbell, L. A., Knack, J. M., Waldrip, A. M., Campbell, S. D., 2007. Do big five personality traits associated with self-control influence the regulation of anger and aggression? Journal of Research in Personality 41 (2), $403-424$.

Ji, Y. G., Hwangbo, H., Yi, J. S., Rau, P. L. P., Fang, X., Ling, C., 2010. The influence of cultural differences on the use of social network services and the formation of social capital. International Journal of HumanComputer Interaction 26 (11-12), 1100-1121.

Jochen, P., Valkenburg, P. M., Schouten, A. P., 2005. Developing a Model of Adolescent Friendship Formation on the Internet. CyberPsychology \& Behavior 8 (5).

Jurgenson, N., 2012. When atoms meet bits: Social media, the mobile web and augmented revolution. Future Internet $4(1), 83-91$.

Kagel, J., Roth, A. (Eds.), 1995. The Handbook of Experimental Economics. Princeton University Press.

Kahneman, D., 2011. Thinking, fast and slow. Allen Lane.

Koot, H., Garde, H., 2013. Online adolescence: Real-life development in the virtual world of warcraft. In: Schousboe, I., Winther-Lindqvist, D. (Eds.), Children's Play and Development. Vol. 8 of International perspectives on early childhood education and development. Springer Netherlands, pp. 165-180.

Krauss, R., Fussell, S., 1991. Perspective-taking in communication: Representations of others' knowledge in reference. Social Cognition 9 (1), 2-24.

Kuhlman, D., Marshello, F., 1975. Individual differences in game motivation as moderators of preprogrammed strategy effects in prisoner's dilemma. Journal of Personality and Social Psychology 32 (5), 922-931.

Landis, J. R., Koch, G. G., 1977. The measurement of observer agreement for categorical data. Biometrics $33(1), 159-174$.

Laumann, E., 1966. Prestige and Association in an Urban Community. Bobbs-Merrill.

Lazarsfeld, P., Merton, R., 1954. Freedom and control in modern society. Van Nostrand, New York, NY, USA, Ch. Friendship as a social process: a substantive and methodological analysis.

Lee, J.-E. R., Moore, D. C., Park, E.-A., Park, S. G., 2012. Who wants to be "friend-rich"? social compensatory friending on facebook and the moderating role of public self-consciousness. Computers in Human Behavior 28 (3), 1036 - 1043. 
Liebrand, W., Jansen, R., Ruken, V., Suhre, C., 1986a. Might over morality: Social values and the perception of other players in experimental games. Journal of Experimental Social Psychology 22, 203-215.

Liebrand, W., van Run, G., 1985. The effects of social motives on behavior in social dilemmas in two cultures. Journal of Experimental Social Psychology 21, 86-102.

Liebrand, W., Wilke, W., Vogel, R., Wolters, F., 1986b. Value orientation and conformity: A study using three types of social dilemma games. Journal of Conflict Resolution 30 (1), 77-97.

Lounsbury, J., Moffitt, L., Gibson, L., Drost, A., Stevens, M., 2007. An investigation of personality traits in relation to job and career satisfaction of information technology professionals. Journal of Information Technology 22, 174-183.

Maio, G., Olson, J., Allen, L., Bernard, M., 2001. Addressing discrepencies between values and behavior: the motivating effect of reason. Journal of Experimental Social Psychology 37, 104-117.

Majolo, B., Ames, K., Brumpton, R., Garratt, R., Hall, K., Wilson, N., 2006. Human friendship favours cooperation in the iterated prisoner's dilemma. Behaviour 143 (11), 1383-1395.

Marcus, B., Machilek, F., Sch`utz, A., 2006. Personality in cyberspace: personal web sites as media for personality expressions and impressions. Journal of Personality and Social Psychology 90 (6), 10141031.

Marks, P., Polak, P., McCoy, S., Galletta, D., 2008. Sharing knowledge. Communications of the ACM 51 (2), 60-65.

McClintock, C., 1978. Social values: Their definition, measurement and development. Journal of Research and Development in Education 12 (1), 121-137.

McClintock, C., Allison, S., 1989. Social value orientation and helping behaviour. Journal of Applied Social Psychology 19, 353-362.

McClintock, C., W.B.G., L., 1988. The role of interdependence structure, individual value orientation, and other's strategy in social decision making: a tranformational analysis. Journal of Personality and Social Psychology 55, 396-409.

McElroy, J. C., Hendrickson, A. R., Townsend, A. M., Demarie, S. M., 2007. Dispositional factors in internet use: Personality versus cognitive style. MIS Quarterly 31 (4).

McPherson, J., Smith-Lovin, L., 1987. Homophily in voluntary organizations: status distance and the composition of face to face groups. American Sociological Review 52, 370-379.

McPherson, M., Smith-Lovin, L., Cook, J., 2001. Birds of a feather: homophily in social networks. Annual Review of Sociology 27, 415-444.

Messick, D. M., McClintock, C. G., 1968. Motivational bases of choice in experimental games. Journal of Experimental Social Psychology 4 (1), 1-25.

Messinger, P., Ge, X., Stroulia, E., Lyons, K., Smirnov, K., Bone, M., 2008a. On the relationship between my avatar and myself. Journal of Virtual Worlds Research 1 (2).

Messinger, P., Stroulia, E., Lyons, K., 2008b. A typology of virtual worlds: historical overview and future 
directions. Journal of Virtual Worlds Research 1 (1).

Moody, J., 2001. Race, school integration, and friendship segregation in american. American Journal of Sociology 107, 679-716.

Moore, K., McElroy, J. C., 2012. The influence of personality on facebook usage, wall postings, and regret. Computers in Human Behavior 28 (1), 267 - 274.

Munn, N., 2012. The reality of friendship within immersive virtual worlds. Ethics and Information Technology $14,1-10$.

Nettle, D., 2006. The evolution of personality variation in humans and other animals. American Psychologist $61(6), 622-631$.

Nisbett, R., 2010. The geography of thought: How Asians and Westerners think differently. Simon and Schuster.

Nowak, K. L., Rauh, C., 2006. The influence of the avatar on online perceptions of anthropomorphism, androgyny, credibility, homophily, and attraction. Journal of Computer-Mediated Communication 11 (1), $153-178$.

Ollington, N., Gibb, J., Harcourt, M., 2013. Online social networks: an emergent recruiter tool for attracting and screening $42(3), 248-265$.

Olver, J. M., Mooradian, T. A., 2003. Personality traits and personal values: a conceptual and empirical integration. Personality and Individual Differences 35 (1), 109 - 125.

Orucevic-Alagic, A., Host, M., Aug 2014. Network analysis of a large scale open source project. In: Software Engineering and Advanced Applications (SEAA), 2014 40th EUROMICRO Conference on. pp. 25-29.

Parks, L., 2007. Personality and values: a meta analysis. In: Annual conference for the society of industrial and organizational psychology. New York, NY, USA.

Parks, L., Guay, R. P., 2009. Personality, values, and motivation. Personality and Individual Differences $47(7), 675-684$.

Quyen, L., Zaharim, N., 2012. The relationship between friendship characteristics, ethnic identity and value systems of youths from ethnic groups in vietnam: a conceptual framework for research. International Journal of Humanities and social science 2 (23), 133-139.

Rentfrow, P., Gosling, S., 2006. Message in a ballad: the role of music preferences in interpersonal perception. Psychological Science 17 (3), 236-242.

Rheingold, H., 2000. The virtual community: Homesteading on the electronic frontier. MIT Press.

Roccas, S., Sagiv, L., Schwartz, S. H., Knafo, A., 2002. The big five personality factors and personal values. Personality and Social Psychology Bulletin 28 (6), 789-801.

Rokeach, M., 1973. The nature of human values. The Free Press.

Rosenfeld, L. B., Plax, T. G., 1977. Clothing as communication. Journal of Communication 27 (2), 24-31.

Ross, C., Orr, E. S., Sisic, M., Arseneault, J. M., Simmering, M. G., Orr, R. R., 2009. Personality and motivations associated with facebook use. Computers in Human Behavior 25 (2), 578 - 586. 
Ruef, M., Aldrich, H., Carter, N., 2003. The structure of founding teams: homophily, strong ties and isolation among us entrepreneurs. American Sociological Review 68, 195-222.

Sattler, D., Kerr, N., 1991. Might versus morality explored: Motivational and cognitive bases for social motives. Journal of Personality and Social Psychology 60, 756-765.

Schelling, T., 1960. The Strategy of Conflict. Harvard University Press.

Schiano, D. J., Nardi, B., Debeauvais, T., Ducheneaut, N., Yee, N., forthcoming. The "lonely gamer" revisited. Entertainment Computing.

Scholte, R. H., van Aken, M. A., van Lieshout, C. F., 1997. Adolescent personality factors in self-ratings and peer nominations and their prediction of peer acceptance and peer rejection. Journal of Personality Assessment 69 (3), 534-554.

Schwartz, S., 1994. Are there universal aspects in the structure and contents of human values. Journal of Social Issues 50 (4), 19-45.

Schwartz, S., 2010. Prosocial motives, emotions, and behavior: The better angels of our nature. American Psychological Association, Ch. Basic values: how they motivate and inhibit prosocial behavior, pp. $221-241$.

Seeland, K., Dübendorfer, S., Hansmann, R., 2009. Making friends in zurich's urban forests and parks: The role of public green space for social inclusion of youths from different cultures. Forest Policy and Economics 11 (1), $10-17$.

Selfhout, M., Branje, S., Meeus, W., 2007. Similarity in adolescent best friendships: the role of gender. Netherlands journal of psychology 63, 42-48.

Selfhout, M., Burk, W., Branje, S., Denissen, J., van Aken, M., Meeus, W., 2010. Emerging late adolescent friendship networks and big five personality traits: a social network approach. Journal of Personality $78(2), 509-538$.

Søraker, J., 2012. How shall i compare thee? comparing the prudential value of actual and virtual friendship. Ethics and Information Technology 14, 209-219.

Sprecher, S., Regan, P. C., 2002. Liking some things (in some people) more than others: Partner preferences in romantic relationships and friendships. Journal of Social and Personal Relationships 19 (4), 463-481.

Tajfel, H., 1978. Differentiation between social groups. Academic Press.

Talamo, A., Ligorio, B., 2001. Strategic identities in cyberspace. Cyberpsychology and Behaviour 4 (1), $109-122$.

Taylor, T., 2002. The social life of avatars: presence and interaction in shared virtual environments. Springer Verlag, Ch. Living digitally: embodiment in virtual worlds, pp. 40-62.

Thelwall, M., 2009. Homophily in myspace. Journal of the American Society for Information Science and Technology 60 (2), 219-231.

Turner, J., 1987. Rediscovering the Social Group: A Self-categorization theory. Blackwell Publishing Ltd.

Utz, S., 2000. Social information processing in muds: the development of friendship in virtual worlds. Journal 
of Online Behavior 1 (1).

Vallor, S., 2012. Flourishing on facebook: Virtue friendship and new social media. Ethical of Information Technology 14, 185-199.

Van Lange, P., Agnew, C., Harinck, F., Steemers, G., 1997a. From game theory to real life: How social value orientation affects willingness to sacrifice in ongoing close relationships. Journal of Personality and Social Psychology 73 (6), 1330-1344.

Van Lange, P., Bekkers, R., Schuyt, T., Vugt, M., 2007. From games to giving: Social value orientation predicts donations to noble causes. Basic and Applied Social Psychology 29 (4), 375-384.

Van Lange, P., De Bruin, E., Otten, W., Joireman, J., 1997b. Development of prosocial, individualistic and competitive orientations: Theory and preliminary evidence. Journal of Personality and Social Psychology 73 (4), 733-746.

Van Lange, P., Kuhlman, D., 1994. Social value orientations and impressions of partner's honesty and intelligence: A test of the might versus morality effect. Journal of Personality and Social Psychology $67,126-141$.

Van Lange, P., Liebrand, W., 1991. The influence of other's morality and own social value orientation on cooperation in the netherlands and the usa. International Journal of Psychology 26 (4), 429-449.

Van Vugt, M., Meertens, R., Van Lange, P., 1995. Car versus public transportation? the role of social value orientations in a reallife social dilemma. Journal of Applied Social Psychology 25 (3), 187-278.

Van Zalk, M. H. W., Branje, S. J. T., Denissen, J., Van Aken, M. A. G., Meeus, W. H. J., 2011. Who benefits from chatting, and why? the roles of extraversion and supportiveness in online chatting and emotional adjustment. Personality and Social Psychology Bulletin 37 (9), 1202-1215.

Veage, S., Ciarrochi, J., Heaven, P. C., 2011. Importance, pressure, and success: Dimensions of values and their links to personality. Personality and Individual Differences 50 (8), 1180 - 1185.

Verplanken, B., Holland, R., 2002. Motivated decision-making: Effects of activation and self-centrality of values on choices and behavior. Journal of Personality and Social Psychology 82 (3), 434-447.

Wasko, M., Teigland, R., Leidner, D., Jarvenpaa, S., 2011. Stepping into the internet: new ventures in virtual worlds. MIS Quarterly 35 (3), 645-652.

Watters, E., 2004. Urban Tribes: Are Friends the New Family? Bloomsbery.

Wherli, S., 2008. Personality on social network sites: An application of the five factor model. ETH Zurich Working Paper Series Paper No. 7.

URL http://ideas.repec.org/p/ets/wpaper/7.html

Wrosch, C., Scheier, M., 2003. Personality and quality of life: The importance of optimism and goal adjustment. Quality of Life Research 12 (1), 59-72.

Yang, C.-c., Brown, B., 2013. Motives for using facebook, patterns of facebook activities, and late adolescents' social adjustment to college. Journal of Youth and Adolescence 42 (3), 403-416.

Yee, N., 2006. The demographics, motivations and derived experiences of users of massively multi-user online 
graphical environments. Presence 15 (3), 309-329.

Yee, N., Bailenson, J., 2007. The proteus effect: the effect of transformed self-representation on behavior. Human Communication Research 33, 271-290.

Yee, N., Ducheneaut, N., Nelson, L., Likarish, P., 2011a. Introverted elves and conscientious gnomes: the expression of personality in world of warcraft. In: Proceedings of the SIGCHI Conference on Human Factors in Computing Systems. CHI '11. ACM, New York, NY, USA, pp. 753-762.

Yee, N., Harris, H., Jabon, M., Bailenson, J. N., 2011b. The expression of personality in virtual worlds. Social Psychological and Personality Science 2 (1), 5-12. 